\title{
High-response intrauterine insemination cycles converted to low-cost in vitro fertilization
}

This article was published in the following Dove Press journal: Journal of Multidisciplinary Healthcare

10 May 2011

Number of times this article has been viewed

\author{
Fatma Aletebi \\ Assisted Reproduction Unit, \\ Department of Obstetrics and \\ Gynaecology, King Abdulaziz \\ University, Soliman Fakeeh Hospital, \\ Jeddah, Saudi Arabia
}

Background: There is a trend to cancel intrauterine insemination (IUI) in women with a high response. The aim of this study was to evaluate the efficacy of low-cost in vitro fertilization (IVF) in high-response IUI cycles in comparison with conventional IVF.

Methods and materials: A total of 46 women were included in the study. Group A (study group) included 23 women with hyper-response to IUI cycles who were converted to IVF. They received oral letrozole $2.5 \mathrm{mg}$ twice daily from days 3-7 of the menstrual cycle, along with 75 International Units (IU) of recombinant follicle-stimulating hormone on days 3 and 8 . Group B (control group) underwent conventional IVF, and received downregulation with a gonadotrophinreleasing hormone agonist followed by stimulation with recombinant follicle-stimulating hormone 150-300 IU/day. Ovulation was triggered by 10,000 IU of human chorionic gonadotrophin, followed by IVF and embryo transfer. The primary outcome measure analyzed was pregnancy rates in both groups.

Results: The study group received a significantly lower $(P=0.001)$ total dose of folliclestimulating hormone and had significantly $(P=0.002)$ decreased levels of terminal estradiol. Although the pregnancy rate $(30.43 \%$ in the study group versus $39.13 \%$ in the conventional group) per stimulated cycle was higher in the conventional IVF group, the miscarriage rate (study group 4.34\% versus conventional group 13.04\%) was also higher, and hence the takehome baby rate (study group $26.08 \%$ versus conventional group $30.43 \%$ ) was more or less similar in both the groups.

Conclusion: IVF can be offered to women having a high response to IUI cycles with good pregnancy rates and at low cost compared with use of a conventional protocol, and therefore can be considered more patient-friendly in selected cases.

Keywords: low-cost, mild stimulation, intrauterine insemination, in vitro fertilization

\section{Introduction}

Since the birth of the first in vitro fertilization (IVF) baby almost 30 years ago, dramatic developments have occurred in assisted reproductive technology. The approach of maximizing pregnancy rates per cycle has led to very complex and costly ovarian hyperstimulation protocols. Ovarian stimulation has been applied with the aim of increasing the number of oocytes in order to compensate for inefficiencies of the IVF procedure, enabling the selection of one or more embryos for transfer. ${ }^{1}$ In the context of improved laboratory performance, the need for a large number of oocytes as an integral part of a successful IVF program may be questioned.

Currently used medication regimens for ovarian stimulation are complex, expensive, may require weeks of daily injections, and intense ovarian response monitoring
Correspondence: Fatma Aletebi Department of Obstetrics and Gynaecology, King Abdulaziz University, Soliman Fakeeh Hospital, Jeddah, Saudi Arabia

Tel +966503002383

Emailfaletebi@yahoo.com 
is usually needed. Such regimens are associated with the risk of complications, such as ovarian hyperstimulation syndrome ${ }^{2-4}$ and impaired luteal phase. Other negative effects associated with ovarian stimulation include emotional stress, high dropout rates, and abdominal discomfort. ${ }^{1}$ Moreover, uncertainties remain regarding long-term health risks (such as ovarian cancer) and an increased incidence of low birth weight and birth defects in the offspring conceived following IVF treatment..$^{5-8}$ Some investigators suggest poor embryo quality and chromosomal abnormalities associated with ovarian stimulation. ${ }^{9}, 10$ In contrast with current approaches, mild ovarian stimulation for IVF intends to limit the number of oocytes obtained to fewer than eight, ${ }^{11,12}$ with an acceptable pregnancy rate.

In 1996, Edwards et al were the first to express concern with regard to contemporary ovarian stimulation approaches for IVF and called for the use of a milder stimulation protocol. ${ }^{13}$ The aim of mild stimulation is to develop safer and more patient-friendly protocols in which the risks of treatment are minimized. $2,6,11,14-17$

The term "low-cost IVF" was coined by Professor Alan Trounson at a World Health Organization meeting in Geneva in 2001. The concern of the World Health Organization had always been to promote advances in health care in lowresource economies. A milder stimulation protocol offers the same advantages as natural-cycle IVF, but has higher efficacy by recruiting one dominant follicle in addition to a few codominant follicles that do not develop spontaneously in a natural cycle. ${ }^{2,18}$ However, there are reservations about the efficacy of a low-dose approach, including lower pregnancy rates compared with conventional IVF, in addition to a lower profit for IVF centers. In some cases when undergoing intrauterine insemination (IUI), taking 75 International Units (IU) of human menopausal gonadotrophin will result in a high response with many follicles developing leading to subsequent cancellation for fear of multiple pregnancy or severe ovarian hyperstimulation syndrome. The aim of the present study was to evaluate the efficacy of rescue IVF in high-response IUI cycles (ie, low-cost IVF) compared with a conventional protocol.

\section{Materials and methods Selection of participants}

The study was performed at King Abdel Aziz University Hospital between October 2008 and April 2010. Approval by the research ethics board of the institution was obtained, and written consent was obtained from all patients after careful counseling. During the study period, we had 46 women scheduled for IUI and those having a high response were recruited for the study. All these women underwent both ultrasound and endocrine assessment prior to the beginning of treatment. Those patients who had previously failed IVF or had previous laparotomy were excluded from the study. Patients with moderate to severe endometriosis and a baseline follicle-stimulating hormone level $\geq 12 \mathrm{mIU} / \mathrm{mL}$ were also excluded. Twenty-three women with hyper-response in IUI cycles who subsequently underwent IVF were included in the study group (Group A). Twenty-three women with similar demographic and endocrine characteristics during the same period were randomly selected, excluding any bias, and were included in the control group (Group B) to undergo conventional IVF.

As in traditional ovarian stimulation for IUI, women in Group A received oral letrozole (Letroz ${ }^{\circledR}$, Sun Pharmaceuticals, Mumbai, India) at a dose of $2.5 \mathrm{mg}$ twice daily from days 3-7 of the menstrual cycle, and recombinant follicle-stimulating hormone (Gonal- $\mathrm{F}^{\circledR}$, Serono, Aubonne, Switzerland) was administered subcutaneously at a dose of $75 \mathrm{IU} /$ day on days 3 and 8 of the menstrual cycle. The dose was subsequently adjusted according to the response.

Women in Group B received the conventional protocol for controlled ovarian hyperstimulation, ie, a daily subcutaneous $500 \mu \mathrm{g}$ injection of a gonadotrophin-releasing hormone $(\mathrm{GnRH})$ agonist, leuprolide acetate (Lupride ${ }^{\circledR}$, Sun Pharmaceuticals, Mumbai, India) starting from the mid-luteal phase of the previous cycle and continuing for a period of 14 days, or until the onset of the next menstruation, whichever was earlier. If the patient did not start menstruating by day 14 of GnRH agonist treatment, estradiol and leutinizing hormone levels were assayed and analyzed. Estradiol levels $\leq 10 \mathrm{pg} / \mathrm{mL}$ or leutinizing hormone $\leq 3 \mathrm{mIU} / \mathrm{mL}$ were considered to be evidence of downregulation. If the patient did not meet these criteria, the GnRH agonist was continued for a further four days at the same dose. Recombinant folliclestimulating hormone was administered subcutaneously to the downregulated subjects at a dose of 100-150 IU/day, with subsequent adjustment of the dose according to the dose-response scheme.

All patients were monitored for ovarian follicular development by transvaginal ultrasonography. When the average diameter of the lead follicle(s) reached $\geq 18 \mathrm{~mm}$, blood was drawn for assessment of terminal estradiol, and the women were administered 10,000 IU human chorionic gonadotrophin (Pregnyl ${ }^{\circledR}$, Organon, The Netherlands) subcutaneously 
as a single dose. Oocytes were retrieved by transvaginal ultrasonography 34-36 hours after administration of human chorionic gonadotrophin. The retrieved oocytes were inseminated with spermatozoa from the husband. Embryo transfer was performed 40-42 hours following insemination at the 4-6-cell cleavage stage. All patients received $600 \mathrm{mg}$ micronized progesterone (Utrogestan ${ }^{\circledR}$, Laboratories Besins International, Paris, France) intravaginally daily until a pregnancy test was performed, and, if the test was positive, progesterone treatment was continued up to gestational week 12. Clinical pregnancy was defined when an ultrasound scan, performed five weeks after embryo transfer, revealed the presence of a viable fetus.

\section{Immunoassay of hormones}

Serum levels of leutinizing hormone and follicle-stimulating hormone were measured by a two-site chemiluminescent sandwich immunoassay system (ACS 180, Bayer Diagnostics Corporation, Tarrytown, NY). All samples were assayed in duplicate. The leutinizing hormone and follicle-stimulating hormone values were expressed in terms of the World Health Organization reference standards. Assay sensitivity for follicle-stimulating hormone was $0.3 \mathrm{mIU} / \mathrm{mL}$ and for leutinizing hormone was $0.07 \mathrm{mIU} / \mathrm{mL}$. Estradiol levels were assayed by a fully automated enzyme-linked fluorescence assay system (Vidas ${ }^{\circledR}$, BioMerieux, Marcy-l'Etoile, France). The minimum detection limit was $9 \mathrm{pg} / \mathrm{mL}$. The intra-assay and inter-assay coefficients of variation were $3.46 \%$ and $4.82 \%$ for follicle-stimulating hormone; $4.4 \%$ and $5.6 \%$ for leutinizing hormone; and $4.2 \%$ and $5.2 \%$ for estradiol, respectively. The primary outcome measure was pregnancy outcome, while additional measures included total dose of follicle-stimulating hormone administered, number of mature follicles, levels of terminal estradiol, number of oocytes retrieved, endometrial thickness, and transferable embryos.

\section{Statistics}

Statistical comparisons were performed using the Student's $t$-test and $\mathrm{X}_{2}$-test (v 17: SPSS), as applicable. $P<0.05$ was considered to be statistically significant.

\section{Results}

All patients were euthyroid and normoprolactinemic and both groups were comparable with respect to all baseline clinical and demographic characteristics (Table 1). The composite results of treatment outcome are summarized in Table 2. Compared with the conventional group, the low-cost IVF patients received a much lower total dose of follicle-stimulating hormone and had significantly decreased levels of terminal estradiol. However, the two groups did not differ significantly with respect to the number of matured follicles or endometrial thickness. The number of transferable embryos was significantly lower in the low-cost IVF group than in the conventional group. There were no dropouts from either group. One stimulated cycle (4.34\%) in the low-cost group was cancelled due to poor ovarian response (emergence of no dominant follicle). In the conventional group, three women had ovarian hyperstimulation (Table 3). Although the pregnancy rate per stimulated cycle was higher in the conventional IVF group, the miscarriage rate was also higher, and hence the take-home baby rate was more or less similar in both the groups (Table 4).

\section{Discussion}

Natural cycle IVF and modified natural cycle IVF with use of a GnRH antagonist are cheaper modalities of low-cost IVF. However, their usage is limited by high cancellation rates. Mild stimulation indicates lower doses and fewer days of gonadotrophin administration combined with oral drugs (clomiphene citrate or aromatase inhibitors). This appears to be less complex but with improved compliance. The success of aromatase inhibition by letrozole in inducing ovulation in anovulatory women with polycystic ovarian syndrome ${ }^{19}$ and augmenting ovulation in ovulatory women $^{19,20}$ has been reported previously. It has also been shown that, when letrozole is used with folliclestimulating hormone, a significant reduction occurs in the follicle-stimulating hormone dose needed for controlled ovarian hyperstimulation. ${ }^{20}$ The successful use of letrozole in increasing ovarian sensitivity to gonadotrophins and inducing superovulation prompted us to utilize the same in reducing the cost of IVF by significant reduction of gonadotrophin dosage. Most of the studies undertaken to evaluate the efficacy of low-cost IVF used a combination of clomiphene citrate and gonadotrophins. ${ }^{21-25}$

There is little information about the use of aromatase inhibitors for IVF because the number of series published in the literature is small and the majority of studies are nonrandomized. In a prospective randomized pilot study, Verpoest et $\mathrm{al}^{26}$ showed that response to controlled ovarian stimulation improved with the use of aromatase inhibitors. In normal responders undergoing an ovarian stimulation protocol, women were randomized to receive recombinant folliclestimulating hormone $150 \mathrm{IU}$ and a GnRH antagonist with 
Table I Baseline demographic and clinical characteristics of subjects treated with low-cost IVF and conventional IVF protocols

\begin{tabular}{llllll}
\hline Group* & $\begin{array}{l}\text { Age (years) } \\
\text { mean } \pm \text { SD }\end{array}$ & $\begin{array}{l}\text { Body mass } \\
\text { index }\left(\mathbf{k g} / \mathbf{m}^{2}\right)\end{array}$ & $\begin{array}{l}\text { Basal FSH } \\
(\mathbf{U} / \mathbf{L})\end{array}$ & $\begin{array}{l}\text { Basal leutinizing } \\
\text { hormone }(\mathbf{U} / \mathbf{L})\end{array}$ & $\begin{array}{l}\text { Estradiol } \\
(\mathbf{p g} / \mathbf{m L})\end{array}$ \\
\hline $\begin{array}{l}\text { Low-cost IVF } \\
(\mathrm{n}=23)\end{array}$ & $28.78 \pm 4.9$ & $26.2 \pm 3.1$ & $5.48 \pm 1.29$ & $6.37 \pm 3.25$ & $34.46 \pm 16.62$ \\
$\begin{array}{l}\text { Conventional IVF } \\
(\mathrm{n}=23)\end{array}$ & $29.48 \pm 3.04$ & $26.8 \pm 3.6$ & $5.72 \pm 1.82$ & $6.07 \pm 2.4$ & $45.31 \pm 15.48$ \\
\hline
\end{tabular}

Note: *All patients were euthyroid and normoprolactinemic.

Abbreviations: IVF, in vitro fertilization; FSH, follicle-stimulating hormone.

letrozole $2.5 \mathrm{mg} /$ day during the first five days of stimulation versus no letrozole. A higher number of oocytes retrieved per cycle was documented in the letrozole group (14.8 versus 9.6), although the difference was not statistically significant. Pregnancy outcome was similar in both study groups. A similar result was also observed in the present study due to no significant difference between the two groups.

Goswami et a ${ }^{27}$ reported the first randomized controlled trial to assess whether incorporation of letrozole could be an effective low-cost IVF protocol for poor responders. Women over 35 years of age, who had failed 1-3 previous IVF attempts due to poor ovarian response to a conventional long GnRH agonist stimulation protocol were selected for this study. A total of 13 participants were randomized to letrozole $2.5 \mathrm{mg} /$ day for days 3-7 of the menstrual cycle and subcutaneous recombinant follicle-stimulating hormone at a dose of $75 \mathrm{IU} /$ day on days 3 and 8 , while the remaining 25 participants underwent a long GnRH agonist protocol and were stimulated with recombinant folliclestimulating hormone 300-450 IU/day (controls). Compared with the control group, the letrozole-recombinant folliclestimulating group received a significantly lower total dose of follicle-stimulating hormone and had significantly decreased levels of terminal estradiol. The two groups did not differ with respect to the numbers of matured follicles, retrieved oocytes, transferable embryos, or endometrial thickness. The pregnancy rate per stimulated cycle was also similar. The authors concluded that adjunctive use of letrozole may be an effective low-cost IVF protocol in poorly responding women.
Garcia-Velasco et $\mathrm{a}^{28}$ evaluated the use of letrozole as an adjuvant to follicle-stimulating treatment in IVF cycles of poor responders. To be included in the study, patients had to have at least one previously cancelled IVF attempt in which four or fewer follicles $16 \mathrm{~mm}$ in diameter were obtained. Women were divided into a control group of 76 patients treated with high-dose gonadotrophins in a GnRH antagonist regimen, whereas the experimental group of 71 patients received letrozole $2.5 \mathrm{mg}$ plus gonadotrophins for the first 5 days of stimulation followed by the same GnRH antagonist regimen. The number of oocytes retrieved, intrafollicular levels of androgens, and implantation rates were significantly higher among the letrozole-treated patients. Pregnancy rates were also higher, but the differences were not statistically significant.

Schoolcraft et $\mathrm{al}^{29}$ have recently reported the results of a comparison of the efficacy of a microdose GnRH agonist flare with a GnRH antagonist-letrozole protocol before IVF embryo transfer in poor responders. There were no differences in duration or dose of gonadotrophins required, days of stimulation, numbers of oocytes, percentage of mature oocytes obtained, fertilization rate, and embryo quality. However, ongoing pregnancy rates were significantly lower on the letrozole protocol than on the microdose GnRH agonist flare protocol (37\% versus $52 \%$ ).

Due to the selective inhibition of aromatase, letrozole significantly inhibits the overall production of estrogens. Consequent withdrawal of the negative feedback effects of estrogens may allow the pituitary to produce more endogenous follicle-stimulating hormone. Moreover, attenuated

Table 2 Treatment outcomes in women in low-cost IVF and conventional IVF groups

\begin{tabular}{lccc}
\hline Outcome & Low-cost IVF & Conventional & $P$ value \\
\hline Total dose of FSH (IU) & $1195.65 \pm 609.61$ & $2168.48 \pm 985.87$ & $0.00 I$ \\
Number of mature follicles & $6.26 \pm 2.83$ & $6.83 \pm 3.33$ & 0.539 \\
Estradiol $(\mathrm{pg} / \mathrm{mL})$ & $1775.68 \pm 683.04$ & $2692.61 \pm 1101.12$ & 0.002 \\
Transferred embryos & $4.50 \pm 2.40$ & $7.61 \pm 4.24$ & 0.004 \\
Endometrial thickness & $10.35 \pm 2.42$ & $9.90 \pm 1.61$ & 0.457 \\
\hline
\end{tabular}

Note: Values are mean \pm SD.

Abbreviations: FSH, follicle-stimulating hormone; IVF, in vitro fertilization. 
Table 3 Treatment complications in women in low-cost IVF and conventional IVF groups

\begin{tabular}{|c|c|c|c|}
\hline Outcome & $\begin{array}{l}\text { Low-cost IVF } \\
(n=23)\end{array}$ & $\begin{array}{l}\text { Conventional IVF } \\
(n=23)\end{array}$ & $P$ value \\
\hline Cancellation rate & $1 / 23(4.34 \%)$ & - & 1.000 \\
\hline OHSS rate & - & $3 / 23$ (13.04\%) & 0.040 \\
\hline
\end{tabular}

Abbreviations: IVF, in vitro fertilization; OHSS, ovarian hyperstimulation syndrome.

aromatization may lead secondarily to accumulation of follicular androgens, which may increase follicular sensitivity through amplification of follicle-stimulating hormone receptor gene expression ${ }^{30,31}$ or stimulate insulinlike growth factor-I, which may act in synergy with follicle-stimulating hormone. ${ }^{32}$ All these effects may be very important in the letrozole-mediated promotion of follicular maturation. The higher miscarriage rate in the conventional group may have been due to the adverse effect of the GnRH agonist on the endometrium, affecting endometrial receptivity, and on oocyte quality due to the generation of a high concentration of reactive oxygen species in the follicular fluid.

It may be significant in this context to emphasize that the absence of GnRH downregulation in this proposed lowcost protocol may entail a premature leutinizing hormone surge and luteinization, leading to cancellation of the index cycle. However, possibly due to the small sample size, this problem was not encountered in the present study. The main limitation for our study was the small number of participants which reduces the strength of any conclusion drawn. Another limitation is that the number of patients studied was not established using a power calculation prior to the initiation of the study; statistical analysis was only performed once the study was complete. Ideally, this type of research should be verified by submitting the study to a body such as clinicaltrials.gov, but it took around 2 years to recruit our high responders undergoing IUI. A larger sample size would only be achieved by a multicenter study, preferably an international one.

In conclusion, IVF can be offered to women with highresponse IUI cycles, with good pregnancy rates and at low cost

Table 4 Comparison of pregnancy and miscarriage rates in women in low-cost IVF and conventional IVF groups

\begin{tabular}{llll}
\hline Outcome & $\begin{array}{l}\text { Low-cost IVF } \\
(\mathbf{n}=\mathbf{2 3})\end{array}$ & $\begin{array}{l}\text { Conventional } \\
\text { IVF }(\mathbf{n}=\mathbf{2 3})\end{array}$ & P value \\
\hline Pregnancy rate & $7 / 23(30.43 \%)$ & $10 / 23(43.47 \%)$ & $0.58 \mathrm{I}$ \\
Miscarriage rate & $\mathrm{I} / 23(4.34 \%)$ & $3 / 23(13.04 \%)$ & 0.617 \\
Take-home baby rate & $6 / 23(26.08 \%)$ & $7 / 23(30.43 \%)$ & 1.000 \\
\hline
\end{tabular}

Abbreviation: IVF, in vitro fertilization. compared with a conventional protocol, and can therefore, be considered more patient-friendly in selected cases.

\section{Disclosure}

The author reports no conflict of interest in this work.

\section{References}

1. Fauser BC, Devroey P, Macklon NS. Multiple births resulting from ovarian stimulation for subfertility treatment. Lancet. 2005;365: 1807-1816.

2. Fauser BC, Devroey P, Yen SS, et al. Minimal ovarian stimulation for IVF: Appraisal of potential benefits and drawbacks. Hum Reprod. 1999; 14:2681-2686.

3. Delvigne A, Rozenberg S. Epidemiology and prevention of ovarian hyperstimulation syndrome (OHSS): A review. Hum Reprod Update. 2002;8:559-577.

4. Aboulghar MA, Mansour RT. Ovarian hyperstimulation syndrome: Classifications and critical analysis of preventive measures. Hum Reprod Update. 2003;9:275-289.

5. Hansen M, Kurinczuk JJ, Bower C, Webb S. The risk of major birth defects after intracytoplasmic sperm injection and in vitro fertilization. N Engl J Med. 2002;346:725-730.

6. Olivennes F, Fanchin R, Ledee N, Righini C, Kadoch IJ, Frydman R. Perinatal outcome and developmental studies on children born after IVF. Hum Reprod Update. 2002;8:117-128.

7. Wang YA, Sullivan EA, Black D, Dean J, Bryant J, Chapman M. Preterm birth and low birth weight after assisted reproductive technology-related pregnancy in Australia between 1996 and 2000. Fertil Steril. 2005;83: $1650-1658$.

8. Kapiteijn K, de Bruijn CS, de Boer E, et al. Does subfertility explain the risk of poor perinatal outcome after IVF and ovarian hyperstimulation? Hum Reprod. 2006;21:3228-3234.

9. Katz-Jaffe MG, Trounson AO, Cram DS. Chromosome 21 mosaic human preimplantation embryos predominantly arise from diploid conceptions. Fertil Steril. 2005;84:634-643.

10. Baart EB, Martini E, Eijkemans MJ, et al. Milder ovarian stimulation for in-vitro fertilization reduces aneuploidy in the human preimplantation embryo: A randomized controlled trial. Hum Reprod. 2007;22: 980-988.

11. Nargund G, Frydman R. Towards a more physiological approach to IVF. Reprod Biomed Online. 2007;14:550-552.

12. Zegers-Hochschild F, Adamson GD, de Mouzon J, et al. The ICMART and WHO revised glossary on ART terminology. Hum Reprod. 2009; 24:2683-2687.

13. Edwards RG, Lobo R, Bouchard P. Time to revolutionize ovarian stimulation. Hum Reprod. 1996;11:917-919.

14. Diedrich K, Ferberbaum F. New approaches to ovarian stimulation. Hum Reprod. 1998;13 Suppl 3:1-13.

15. Olivennes F, Frydman R. Friendly IVF: The way of the future? Hum Reprod. 1998;13:1121-1124.

16. Pennings G, Ombelet W. Coming soon to your clinic: Patient-friendly ART. Hum Reprod. 2007;22:2075-2079.

17. Ubaldi F, Rienzi L, Baroni E, et al. Hopes and facts about mild ovarian stimulation. Reprod Biomed Online. 2007;14:675-681.

18. Williams SC, Gibbons WE, Muasher SJ, et al. Minimal ovarian hyperstimulation for in vitro fertilization using sequential clomiphene citrate and gonadotrophin with or without the addition of a gonadotropinreleasing hormone antagonist. Fertil Steril. 2002;78:1068-1072.

19. Mitwally MF, Casper RF. Use of an aromatase inhibitor for induction of ovulation in patients with an inadequate response to clomiphene citrate. Fertil Steril. 2001;75:305-309.

20. Mitwally MF, Casper RF. Aromatase inhibition reduces gonadotrophin dose required for controlled ovarian stimulation in women with unexplained infertility. Hum Reprod. 2003;18:1588-1597. 
21. Dhont M, Onghena A, Coetsier T, De Sutter P. Prospective randomized study of clomiphene citrate and gonadotrophins versus goserelin and gonadotrophins for follicular stimulation in assisted reproduction. Hum Reprod. 1995;10:791-796.

22. Engel JB, Ludwig M, Felberbaum R, Albano C, Devroey P, Diedrich $\mathrm{K}$. Use of cetrorelix in combination with clomiphene citrate and gonadotrophins: A suitable approach to 'friendly IVF'? Hum Reprod. 2002;17:2022-2026.

23. Fiedler K, Krusmann G, von Hertwig I, Schleyer M, Wurfel W. Comparison of Clomid/FSH/HMG for IVF with and without GnRH antagonist. Hum Reprod. 2001;16:72.

24. Lin YH, Hwang JL, Seow KM, Huang LW, Hsieh BC, Tzeng CR. Comparison of outcome of clomiphene citrate/human menopausal gonadotropin/cetrorelix protocol and buserelin long protocol - a randomized study. Gynecol Endocrinol. 2006;22:297-302.

25. Weigert M, Krischker U, Pohl M, Poschalko G, Kindermann C, Feichtinger W. Comparison of stimulation with clomiphene citrate in combination with recombinant follicle-stimulating hormone and recombinant luteinizing hormone to stimulation with a gonadotropinreleasing hormone agonist protocol: A prospective, randomized study. Fertil Steril. 2002;78:34-39.

26. Verpoest WM, Kolibianakis E, Papanikolaou E, Smitz J, Van Steirteghem A, Devroey P. Aromatase inhibitors in ovarian stimulation for IVF/ ICSI: A pilot study. Reprod Biomed Online. 2006;13: 166-172.
27. Goswami SK, Das T, Chattopadhyay R, et al. A randomized single-blind controlled trial ofletrozole as a low-cost IVF protocol in women with poor ovarian response: A preliminary report. Hum Reprod. 2004; 19:2031-2035.

28. Garcia-Velasco JA, Moreno L, Pacheco A, et al. The aromatase inhibitor letrozole increases the concentration of intraovarian androgens and improves in vitro fertilization outcome in low responder patients: A pilot study. Fertil Steril. 2005;84:82-87.

29. Schoolcraft WB, Surrey ES, Minjarez DA, Stevens JM, Gardner DK. Management of poor responders: Can outcomes be improved with a novel gonadotropin-releasing hormone antagonist/letrozole protocol? Fertil Steril. 2008;89:152-156.

30. Vendola KA, Zhou J, Adesanya OO, Weil SJ, Bondy CA. Androgens stimulate early stages of follicular growth in the primate ovary. J Clin Invest. 1998;101:2622-2629.

31. Weil S, Vendola K, Zhou J, Bondy CA. Androgen and folliclestimulating hormone interactions in primate ovarian follicle development. J Clin Endocrinol Metab. 1999;84:2951-2956.

32. Palter SF, Tavares AB, Hourvitz A, Veldhuis JD, Adashi EY. Are estrogen of importance to primate/human ovarian folliculogenesis? Endocr Rev. 2001;22:389-424.
Journal of Multidisciplinary Healthcare

\section{Publish your work in this journal}

The Journal of Multidisciplinary Healthcare is an international, peerreviewed open-access journal that aims to represent and publish research in healthcare areas delivered by practitioners of different disciplines. This includes studies and reviews conducted by multidisciplinary teams as well as research which evaluates the results or conduct of such teams or

\section{Dovepress}

healthcare processes in general. The journal covers a wide range of areas and welcomes submission from practitioners at all levels, from all over the world. The manuscript management system is completely online and includes a very quick and fair peer-review system. Visit http://www.dovepress.com/testimonials.php to read real quotes from published authors. 